\title{
The Effect of Rapid Thoracoabdominal Compressions on Intracranial Pressure in Newborn Lambs
}

\author{
FELIX RATJEN, AXEL TROST, JOCHEN WELKER, PETER SPANGENBERG, AND \\ HANS-GEORG WIESEMANN \\ Departments of Pediatrics [F.R., J.W., H.-G.W.] and Neurosurgery [A.T., P.S.], University of Essen, \\ D-45122 Essen, Germany
} \begin{abstract}
ABSF
Measurements of forced expiratory flow in infants can be
obtained with the rapid thoracoabdominal compression (RTC) technique. To assess the transmission of the chest wall compression pressure into the cerebrum, we have performed intracranial pressure (ICP) measurements during RTCs in newborn lambs. Thirteen lambs were studied during the first $8 \mathrm{~d}$ of life. An epidural pressure transducer was implanted under general anesthesia. Respiratory measurements were performed under sedation with ketamine. RTCs were induced through an inflatable jacket wrapped around the lamb's trunk. RTCs were started with a pressure of $30 \mathrm{~cm} \mathrm{H}_{2} \mathrm{O}$. The compression pressure was increased in steps of $20 \mathrm{~cm} \mathrm{H}_{2} \mathrm{O}$ up to $250 \mathrm{~cm} \mathrm{H}_{2} \mathrm{O}$. Flow and volume were determined with a pneumotachograph attached to a face mask. Transpulmonary pressure $\left(\mathrm{P}_{\mathrm{tp}}\right)$ was measured with an esophageal
\end{abstract}

balloon placed in the lower esophagus. RTCs resulted in proportional increases of $P_{t p}$ and ICP. ICP was lower or equal to $P_{t p}$ in all measurements. No changes in baseline ICP occurred throughout the study period. The maximal ICP observed during RTCs was within the range of pressures observed during crying in newborn infants. These data suggest that the RTC technique can be considered safe even at high compression pressures. (Pediatr Res 38: 664-667, 1995)
Abbreviations
RTC, rapid thoracoabdominal compression technique
ICP, Intracranial pressure
$\mathbf{P}_{\mathrm{tp}}$, transpulmonary pressure
PEFV, partial expiratory flow volume

Spirometric tests are widely used for the assessment of pulmonary function in both children and adults $(1,2)$. Since the methodology requires cooperation, it is unsuitable for infants and younger children. To obtain forced expiratory flows in this age group Adler and Wohl have developed a modification of spirometry which has subsequently been named the RTC technique (3-5). A forced expiratory maneuver is induced by applying an external pressure to the chest wall at the end of inspiration. Generally, compression pressures up to $80 \mathrm{~cm} \mathrm{H}_{2} \mathrm{O}$ have been used in studies of infants. With this technique, PEFV curves can be generated that are comparable in shape to those obtained in older children during voluntary forced expirations (6). However, no information is available on the transmission of jacket compression pressure into other organ systems. As both chest and abdomen are forced in equal proportions during RTCs, no pressure gradient can be expected to exist between the two compartments (7). In contrast, RTCs may be of potential harm for the intracerebral vascular system by increasing

Received September 22, 1994; accepted April 27, 1995.

Correspondence and reprint requests: Dr. Felix Ratjen, Children's Hospital, University of Essen, Hufelandstr. 55, D-45122 Essen, Germany.

Supported by a grant of Deutsche Forschungsgemeinschaft (DFG Ra 430/2-4). intracranial pressure. The aim of this study was therefore to assess the changes in intracranial pressure induced by thoracoabdominal compressions over a wide range of compression pressures in newborn lambs.

\section{METHODS}

Thirteen newborn lambs were studied during the first week of life. All lambs were older than 2 and younger than $8 \mathrm{~d}$ of age. The study was approved by the state review board for animal studies and the ethics committee of the university clinic in Essen. The mean weight was $6.5 \pm 1.9 \mathrm{~kg}$ (mean $\pm \mathrm{SD}$ ) ranging from 3.2 to $8.8 \mathrm{~kg}$. Anesthesia was induced with ketamine $(11 \mathrm{mg} / \mathrm{kg}$ body weight $)$ and xylazine $(0.023 \mathrm{mg} / \mathrm{kg}$ body weight), a muscle-relaxing agent with a short half-life given intramuscularly (8). A 4-cm midline incision was performed at the dorsal portion of the scull. A bore hole of 7-9-mm diameter was generated for the insertion of an epidural catheter with a pressure transducer at its tip (Braun, Melsungen, Germany). The catheter was kept in position by a dermal suture and remained in place throughout the study period. 
Respiratory measurements were performed approximately $30 \mathrm{~min}$ after termination of the anesthesia under sedation with repeated low doses of ketamine $(0.1 \mathrm{mg} / \mathrm{kg}$ body weight $)$ given i.v.. $\mathrm{P}_{\text {tp }}$ was measured using an esophageal balloon catheter. The balloon was $40 \mathrm{~mm}$ long with a maximal inflatable diameter of $7 \mathrm{~mm}$ and a wall thickness of $0.04 \mathrm{~mm}$. The esophageal balloon catheter was attached via stiff tubing to a pressure transducer (Validyne, Northridge, CA). The frequency response curve of the esophageal balloon system was linear up to $10 \mathrm{~Hz}$. The balloon catheter was placed in the lower esophagus and filled with $0.6 \mathrm{~mL}$ of air. This volume represented the almost linear portion of its pressure volume curve. Airway pressure was measured at the airway opening through a small port in the mask with a Validyne pressure transducer. Accuracy of the esophageal pressure measurements was assessed during a respiratory movement against an occluded airway. The ratio of esophageal pressure to airway occlusion pressure was between 0.9 and 1.1 in all lambs. Flow was determined with a Fleisch 0 pneumotachograph attached to a snugly fitting face mask. A close fit was achieved with ultrasound gel (Parker, Orange, NJ). Volume was obtained by electrical integration of the flow signal. An inflatable jacket (MAS, Pittsburgh, PA) was wrapped around the lamb's trunk leaving the extremities outside the jacket. The jacket was attached via wide bore tubing to a pressure reservoir that allowed for rapid inflation of the jacket in less than 100 ms (Monsun-Tison, Darmstadt, Germany). Jacket pressure was measured with an Isotec pressure transducer (Hugo Sachs AG, March, Germany) attached to the end of the wide bore tubing at the jacket outlet. All signals (esophageal pressure, airway pressure, intracranial pressure, jacket pressure, flow, and volume) were displayed simultaneously on a six channel chart recorder (Hugo Sachs AG, March, Germany). Static accuracy of all pressure transducers was tested before and at the end of each individual measurement. The data were also recorded on a 7-channel tape recorder (TEAC, Tokyo, Japan). Flow volume curves were either displayed on a digital storage oscilloscope connected to a printer (HAMEG, Frankfurt, Germany) or printed directly on a XY recorder (Rhode \& Schwarz, Munich, Germany).

Rapid thoracoabdominal compressions were performed by switching a three way valve to the pressure reservoir at the end of inspiration. Compressions were started with a jacket pressure of $30 \mathrm{~cm} \mathrm{H}_{2} \mathrm{O}$. The pressure was increased in steps of 20 $\mathrm{cm} \mathrm{H}_{2} \mathrm{O}$ up to compression pressures of 200 to $250 \mathrm{~cm} \mathrm{H}_{2} \mathrm{O}$. The total duration of respiratory measurements was 60 to 120 $\min$.

To assess ICP during physiologic activities, ICP measurements were also performed during spontaneous vocalization (bleating) after termination of the respiratory measurements. Baseline intracranial pressure was also studied on $\mathrm{d} 2$ and 3 after the implantation of the catheter to evaluate whether the chest wall compressions resulted in a secondary increase of intracranial pressure. Subsequently the epidural pressure transducer was removed under anesthesia with ketamine $(11 \mathrm{mg} / \mathrm{kg}$ body weight, intramuscularly). The lambs were observed by a veterinarian up to $7 \mathrm{~d}$ when all sutures could be removed. A final examination by the veterinarian concluded the study in all lambs.

\section{RESULTS}

The insertion of the epidural catheter was successful in all cases and well tolerated throughout the study period. The epidural catheter could be removed after $5 \mathrm{~d}$ without complications in all lambs. Three lambs developed streptococcal meningitis 5-7 d after the catheter was removed and had to be killed. Due to malfunction of the epidural pressure transducer in one animal, ICP measurements could be performed in only 12 of the 13 lambs. The baseline intracranial pressure was 4-8 $\mathrm{cm} \mathrm{H}_{2} \mathrm{O}$ depending on the phase of respiration. There was no apparent effect of ketamine on the respiratory pattern In addition, no changes in baseline intracranial pressure in relation to the repeated i.v. doses of ketamine could be observed $A$ representative tracing of intracranial pressure during a thoracoabdominal compression is shown in Fig 1. There was no change in baseline intracranial pressure throughout the study period in any lamb. Thoracoabdominal compressions resulted in increases of transpulmonary pressure that were proportional to the applied pressure (Fig. 2). The proportion of pressure transmitted through the chest wall was independent of the absolute pressure and approximated $40 \%$ in all sheep at compression pressures up to $150 \mathrm{~cm} \mathrm{H}_{2} \mathrm{O}$. The pressure transmission was lower at pressures exceeding $150 \mathrm{~cm} \mathrm{H}_{2} \mathrm{O}$ resulting in a curvilinear relationship between the two pressures (Fig. 2). ICP also increased parallel to the applied pressure. The steepness of the regression line was more variable compared with the transpulmonary pressure measurements (Fig. 3). Intracranial pressure was lower than $\mathrm{P}_{\text {tp }}$ during all thoracoabdominal compressions.

The maximal intracranial pressures observed during spontaneous vocalization were highly variable and lower than the peak intracranial pressures achieved during thoracoabdominal compressions in 8 out of 12 lambs (Fig. 4). However, 2 lambs showed ICP peaks up to $40 \mathrm{~cm} \mathrm{H}_{2} \mathrm{O}$ during bleating which was very similar to the maximal ICP observed with high thoracoabdominal compression pressures.

\section{DISCUSSION}

Measurements of forced expiratory flow are widely accepted tests for the assessment of pulmonary function. Children older than 3 y of age can actively generate a PEFV curve after an

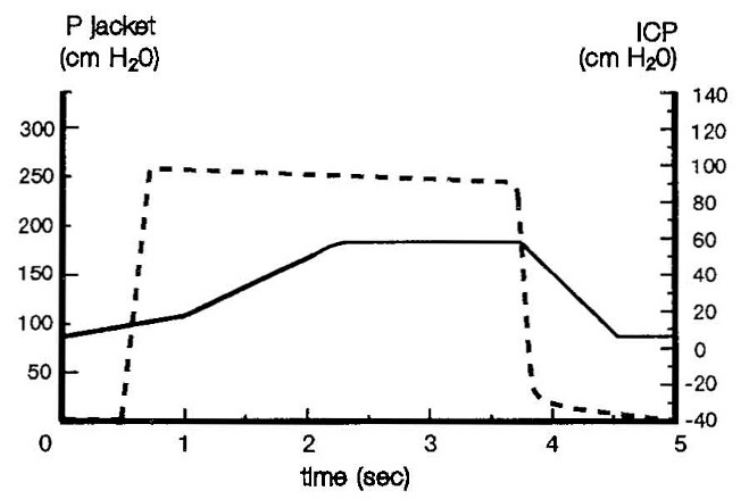

Figure 1. Representative tracing of ICP and jacket compression pressure $\left(P_{\text {jacket }}\right)$ during a rapid thoracoabdominal compression. The solid line represents intracranial pressure; the dashed line jacket pressure. 


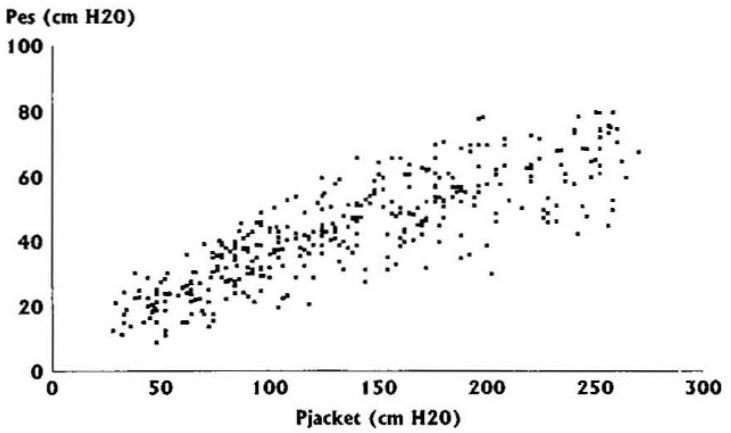

Figure 2. Relationship of jacket compression pressure $\left(P_{\text {jacket }}\right)$ and $\mathrm{P}_{\mathrm{tp}}$ for all 13 lambs. Each square represents one measurement.

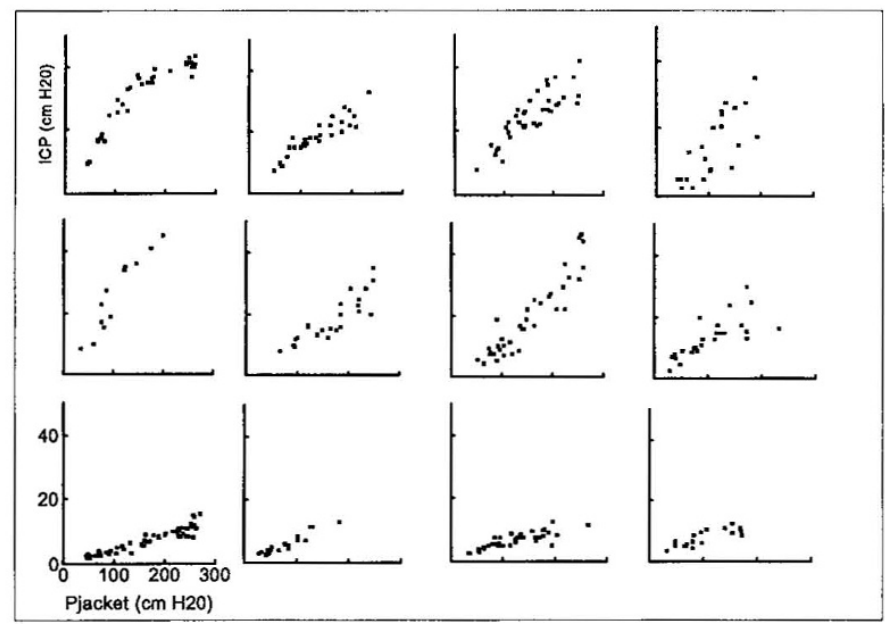

Figure 3. ICP (ordinate) as a function of jacket compression pressure $\left(P_{\text {jacket }}\right.$ abscissa) for all lambs. The scale for ICP ranges from 0 to $50 \mathrm{~cm} \mathrm{H}_{2} \mathrm{O}$ and from 0 to $300 \mathrm{~cm} \mathrm{H}_{2} \mathrm{O}$ for $\mathrm{P}_{\text {jacket }}$, respectively. Each square represents one measurement.

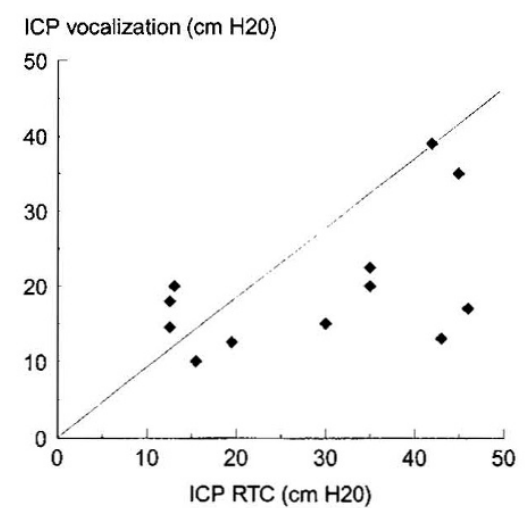

Figure 4. Maximal ICP during rapid thoracoabdominal compressions and spontaneous vocalizations for all lambs. Each square represents the maximal values observed in the individual animal.

inspiration during tidal breathing (6). In children under 3 y of age an external force is being applied to the chest wall through an inflatable jacket at end inspiration (3-5). With this methodology, the RTC technique, a PEFV curve can be obtained that is similar in shape to those actively generated by older children and adults $(6,9)$. However, little is known about the safety of rapid thoracoabdominal compressions in infants. Measurements on the surface of the chest wall have shown that the force during a RTC maneuver is equally distributed between the abdomen and thorax (7). As the force is only applied for a period of $2-3 \mathrm{~s}$, it is not expected to have a significant effect on the cardiovascular system. However, thoracoabdominal compressions may result in changes of intracranial pressure by increasing central venous pressure. This effect may be particularly relevant in young infants whose intracerebral vascular system is more sensitive to injury as reflected by the higher incidence of intraventricular hemorrhage in this age group (10).

The results of this study demonstrate that ICP increases parallel to the compression pressure during a forced expiratory maneuver in newborn lambs. ICP instantaneously returns to baseline after termination of the thoracoabdominal compression. Acute peaks in ICP have been described in a variety of circumstances: During a Valsalva maneuver ICP increases up to $200 \mathrm{~cm} \mathrm{H}_{2} \mathrm{O}$ in adults, a finding that is used diagnostically to rule out obstruction of cerebrospinal fluid circulation (11). Although this test has not been used in infants, newborn infants are known to generate expiratory airway pressures up to 120 $\mathrm{cm} \mathrm{H}_{2} \mathrm{O}$ during crying against an occluded airway (12). Only limited information is available on the changes of pleural pressures induced by spontaneous activities in infants. Transdiaphragmatic pressures during natural crying have been reported to be lower compared with crying against an occluded airway (13). However, noninvasive and invasive measurements of intracranial pressure in newborn infants have shown that crying increases ICP by approximately $40 \mathrm{~cm} \mathrm{H}_{2} \mathrm{O}$; pressures very similar to the maximal intracranial pressures that we have observed at jacket compression pressures of $250 \mathrm{~cm} \mathrm{H}_{2} \mathrm{O}(14$, 15). These data suggest that the higher compression pressures used in this study can also be expected to have no deleterious effect on the intracerebral structures in infants.

We have used ketamine as a sedative agent during rapid thoracoabdominal compressions in this study. Ketamine has previously been shown to have no effect on intracranial pressure when administered in low doses (16). Our results are in concordance with these data, as no changes in ICP were observed after repeated i.v. injections of ketamine. However, we have no information whether pressure transmission has been affected by ketamine as sedation was necessary to perform RTC in these lambs and no measurements could be performed during natural sleep. If at all, sedation would be expected to facilitate pressure transmission by reducing muscle tone which would imply that lower pleural pressures and therefore lower intracranial pressures may be found in unsedated animals. The pressure transmission observed in this study was higher than that reported previously for unsedated newborn infants where only $25 \%$ of the compression pressure was transmitted at end-expiration (4). It can therefore be expected that peak intracranial pressures during thoracoabdominal compressions in unsedated newborn infants are lower than those observed in the present study.

In summary we have shown that ICP increases parallel to the thoracoabdominal compression pressure in newborn lambs. The maximal pressure peaks are within the range of those observed during crying in newborn infants. No changes in baseline ICP were found throughout the study period. These findings suggest that rapid thoracoabdominal compressions can 
be considered safe even at jacket compression pressures exceeding those previously used in infants.

Acknowledgments. We deeply appreciate the expert technical assistance of the P. Bergmann DVM and K. Militzer DVM.

\section{REFERENCES}

1. Fry DL, Hyatt RE 1960 Pulmonary mechanics: a unified analysis of the relationship between pressure, volume and gas flow in the lungs of normal and diseased subjects. Am J Med 29:672-689

2. Mellins RB, Levine OR, Ingram RH, Fishman AP 1968 Obstructive disease of the airways in cystic fibrosis. Pediatrics 41:560-573

3. Adler SM, Wohl MEB 1978 Flow-volume relationships at low lung volumes in healthy newborn infants. Pediatrics 61:636-640

4. Taussig LM, Landau LI, Godfrey S, Arad I 1982 Determinants of forced expiratory flow in newborn infants. J Appl Physiol 53:1220-1227

5. American Thoracic Society/European Respiratory Society 1993 Respiratory mechanics in infants: physiologic evaluation in health and disease. Am Rev Respir Dis 147:474-496

6. Taussig LM 1977 Maximal expiratory flows at functional residual capacity. A test of lung function for young children. Am Rev Respir Dis 116:1031-1038
7. Ratjen F, Zinman R, Wohl MEB 1989 A new technique to demonstrate flow limitation in partial expiratory flow volume curves in infants. J Appl Physiol 67:1662-1669

8. Green CJ, Knight J, Precious S, Simpkin S 1981 Ketamine alone and combined with diazepam or xylazine in laboratory animals: a 10 year experience. Lab Anim $15: 163-170$

9. Bouhuys A, Hunt VR, Kim BM, Zapletal A 1969 Maximum expiratory flow rates in induced bronchoconstriction in men. J Clin Invest 48:59-68

10. Volpe JJ 1989 Intraventricular hemorrhage in the premature infant: neuropathology and pathogenesis. Clin Perinatol 16:361-375

11. Lundberg N 1960 Continuous recording and control of ventricular fluid pressure in neurosurgical practice. Acta Psychiatry Scand 36(suppl 149):22-45

12. Shardonofsky FR, Perez-Chada D, Carmuega E, Milic-Emily J 1989 Airway pressure during crying in infants. Pediatr. Pulmonol. 6:14-18

13. Scott CB, Nickerson BO, Sargent CW, Platzker ACG, Warburton D, Keens TG 1983 Developmental pattern of maximal transdiaphragmatic pressure in infants during crying. Pediatr Res 17:707-709

14. Keith HD, Watts C 1993 Testing of cerebrospinal fluid shunt systems under dynamic flow conditions. Med Instrum 17:297-302

15. Stevens BJ, Johnston CC 1994 Physiologic responses of premature infants to a painful stimulus. Nurs Res 43:226-231

16. Gibbs JM 1972 The effect of intravenous ketamine on cerebrospinal fluid pressure. $\mathrm{Br}$ J Anaesth 44:1298-1302 